\title{
EL DEVENIR MUJER: DE CONTRADICCIONES Y DEMAS PARADOJAS
}

\author{
Micaela Pellegrini (Universidad Nacional de Rosario** \\ micaelapellegrini89@gmail.com
}

Recibido: 30/08/13 Aceptado: 15/11/13

\section{Resumen}

"Recién en una clase al lado mío había una nena que había menstruando por primera vez, puede ser un argumento ante la decisión de que las nenas en Educación Física tengan profesoras mujeres, y los varones profesores varones" (Estudiante del Profesorado en Educación Física, ISEF Nº11, 2013. Rosario).

Utilizaremos dicha cita perteneciente a una entrevista que ha surgido en el marco de la licenciatura en Ciencias de la Educación como pretexto para sumergimos exploratoriamente por primera vez sobre las contradicciones que surgen al pensar a la maternidad vista como la característica fundamental del devenir mujer. A la vez, en función a ello indagamos como paradojal que la mujer haya tenido que padecer en el aislamiento y la soledad avergonzante la función biológica necesaria para dicho rol: la menstruación. Nos proponemos entonces hallar por un lado, líneas simétricas que situaron a la mujer dotada de su máxima expresión de feminidad en el marco de un padecimiento, cuando contradictoriamente, la misma resulta una función fisiológica obligatoria para cumplir con el rol social que se la impuesto como reina del hogar. Por otro lado, buscamos líneas que nos ayuden a pensar esta problemática de manera general en las Escuela y de manera particular en el área de Educación Física, pensada ésta como el espacio educativo en el cual cobra protagonismo el cuerpo y por ello el género.

\section{Palabras claves}

Mujer - Cuerpo - Género - Menstruación - Educación.

* Profesora en Ciencias de la Educación. Facultad de Humanidades y Artes. Universidad Nacional de Rosario. 


\section{Abstract}

"Just now, there was a girl in a class next to me, who menstruated for the first time, this would be an argument to decide wheter the girls at physical education have women teachers, and the boys have men teachers " (student of teacher in physical education, ISEF $N^{\circ} 11,2013$. Rosario).

We will use that event belonging to an interview emerged in the framework of the Bachelor of Science in Education as a pretext to immerse explorative way by first heard about the contradictions arising from view motherhood as a fundamental feature of becoming a woman.

At the same time, based on that, we inquire as paradoxical that the woman has had to suffer in isolation and loneliness embarrassing biological function required for this role: menstruation.

We propose then finding the one hand, contradictory lines that placed the woman endowed with its highest expression of femininity in the context of a condition, when contradictorily, the same physiological function is mandatory to fulfill the social role that has been imposed as queen of the home, and on the other hand, lines that help us think about this problem in the school, institution reproductive hegemonic models must be Female.

\section{Key words}

Woman - Body - Gender - Menstruation - Education.

\section{Lecciones sobre lo que debes "ser" para ser una buena Mujer, una buena Madre y una buena Esposa}

Los orígenes del tema trabajado lo ubicamos en los primeros escritos de Simone de Beauvoir (1948-1949), quien se explayó sobre las diferencias que se conciben entre las mujeres y los varones sin existir conceptualmente lo que hoy conocemos como teoría de género; esta autora ya en los años medios del siglo XIX nos hizo pensar sobre el lugar de subordinación que ha sufrido la mujer durante muchos siglos. La escritora realiza una ardua crítica sobre el lugar social, político y económico del sexo femenino desde los años más primitivos de la sociedad, inclusive desde la mitología griega en la cual ya es posible visualizar el esquema binario y divisorio mujer/varón.

Simone ante la observación minuciosa de esta división que se vuelve jerarquizarte, instaura un nuevo concepto que esquematiza la discriminación resultante de las relaciones entre las mujeres y los varones: lo Mismo y lo Otro (Simone de Beauvoir, 1948-1949: 4):

Ningún sujeto se plantea, súbita y espontáneamente, como lo inesencial; no es lo Otro lo que, al definirse como Otro, define lo Uno, sino que es planteado como Otro por lo Uno, al plantearse este como Uno. Mas, para que no se produzca el retorno de lo Otro a lo Uno, es preciso que lo Otro se someta a este punto de vista 
extraño. ¿De dónde le viene a la mujer esta sumisión? (Simone de Beauvoir,1948-1949: 5).

Para Simone de Beauvoir (1948-1949), las mujeres no resultan el grupo de lo Otro como desenlaces de algún acontecer histórico o por los determinados hechos y/o accidentes que la han colocado en ese lugar; sino que realizando un estudio historiográfico la misma ha podido encontrar que la mujer siempre se ha ubicado en esa estratificación de inferioridad o de incompletud en relación a los varones y esto se ha debido, exclusivamente, a su sistema fisiológico y biológico.

Al ser la mujer poseedora del útero, ovarios y vagina, se convierte en la encargada del cuidado exclusivo de la especie. Su rol maternal, no sólo tiene la finalidad de reproducir su raza, sino que a través de un discurso moderno y capitalista, se instala en la sociedad el falso innatismo o esencialismo materno, es decir, un conjunto de símbolos enmarcados en pretextos morales que se constituyen como el deber ser de una madre abocada exclusivamente al amor de sus hijos.

En vinculación a ello, Ana María Fernández (1993) también investigó sobre el tema y propone pensar a las relaciones entre mujeres y varones como "un pacto sexual legitimador" (Fernandez, 1993: 18), a partir del cual la mujer queda inferiorizada social, cultural y económicamente. Fundamentalmente, la naturalización subordinante de la mujer se ha basado según la autora, desde la dependencia económica y la heteronomía erótica de la misma; fundamentado su tesis a partir de la construcción social de tres mitos constatados falsamente por las ciencias de la medicina y la fisiología: la pasividad erótica femenina, la mujer-madre y el amor romántico.

De acuerdo al mito Mujer: Madre, se establece la completud femenina cuando la mujer termina convirtiéndose como tal. Según Fernández la maternidad vista como la esencia de la mujer, no posee el mismo significante que la reproducción ya que, esta última, se refiere a la perpetuación de la especia, mientras que la maternidad se constituye como un sentimiento cultural del cual se establecen un conjunto de prescripciones que abalan las prácticas propias del ser madres, así como el concebir, parir y criar a los hijos. Dentro de este conjunto de símbolos se enaltece el único proyecto de vida de la mujer, encargada ahora de servir a su familia.

Según Tubert (1996), este sistema de símbolos maternales que se materializan en el rol materno de la mujer, se encuentran presentes en la mayoría de las sociedades occidentales enmarcadas éstas en la organización patriarcal. Se identifican a las mujeres directamente y únicamente con el ser madres, debido consecuentemente a sus funciones biológicas respaldadas por discursos esencialistas e innatitas sobre la femineidad y la maternidad.

Elizabeth Badinter (1981), también teoriza sobre ello en su trabajo ¿Existe el amor maternal? aludiendo a la construcción de discursos científicos, médi- 
cos, moralistas, etc, sobre la existencia de un instinto maternal; por lo cual, establecieron la equivalencia mujer: madre, sometiéndolas a éstas a su misión natural más allá de sus elecciones de vida.

Podemos ahondar aún más profundo y vincular a la construcción del sentimiento maternal, con el sentimiento de infancia (Ariés, 1996) como necesarias para pensar la creación de la familia nuclear, entendiéndola como unidad económica necesaria para el funcionamiento del capitalismo. Nos sumergimos en esta temática ya que consideramos que la mujer fue entendida como poseedora de un "innatismo" maternal que justificaría su función social en la esfera privada de la sociedad, constituyente fundamental de las relaciones de poder perversamente asimétricas en relación a la esfera pública en la cual pertenecen los varones.

Desde su parecer psicológico, Fernández (1993) nos ayuda a esclarecer estos postulados a través de su concepto epistémico sobre la diferencia de los géneros: La Epistemes de lo Mismo. La autora sostiene que existen a priori históricos que constituyen las posibilidades para que se establezca una teoría poseedora de prácticas, mitos, ilusiones, etc. Es decir, en nuestro caso, los mitos que sostienen a la feminidad resultan como propios de una cultura contextuada en un tiempo y un espacio determinado y con aconteceres históricos a priori que los hacen posibles.

Siguiendo esta línea de investigación, en la Modernidad el Hombre se constituye como "la medida de todas las cosas", en él, sostiene Fernández (1993), existe solo él, en cuanto se constituye como lo mismo. A partir de esta constitución, todo lo que se encuentre fuera de lo mismo, no será visto como lo otro, sino que será visto como margen, negatividad, doble, sombra, reverso, complemento. (Fernández, 1993:34). Aquí lo mismo se constituye como lo único, y lo único es el Hombre.

Es así, como sostenida por el naturalismo, el biologismo y el esencialismo, en la Epistemes de lo Mismo la diferencia se constituye como piedra jerarquizante, en la cual la mujer se identifica como naturaleza, inmediatez, intuición, objeto, matrimonio, privado, género; mientras que el Hombre es poseedor de la cultura, la medición, abstracción, sujeto, individuo, metáfora, público (Fernández, 1993:40). Estos postulados fueron por lo tanto motivos que la Mujer en tanto vista como un accidente, como un error, se la ubica jerárquicamente por debajo del Hombre:

¿Qué es la mujer? La Mujer es una ilusión. Una invención social compartida y recreada por hombres y mujeres. Una imagen producto del entrecruzamiento de diversos mitos del imaginario social, desde el cual los hombres y mujeres- en cada período histórico- intentan dar sentido a sus prácticas y discursos (Ana María Fernández, 1993: 22). 
Ahora bien, recapitulando lo que hemos explayado hasta el momento, es notable considerar que la mujer en tanto cuerpo biológico formado sexualmente para la procreación y considerada como "buena madre" desde el simbolismo cultural, la misma posee como función fisiológica necesaria la menstruación. Dicha característica femenina en su máxima expresión, ha sido durante muchos años (y lo sigue siendo hasta el día de hoy) motivo de vergüenza, de impureza, de ocultamiento, una especie de tiempo suspendido para ella.

Es Frente a esta problemática, que a continuación, pasaremos a pensar cuales han sido los sentidos que históricamente se le ha atribuido a la menstruación, a fin de pensarla tanto en términos contradictorios y hasta paradojales en vinculación al feminismo y la maternidad; como así también su lugar como referentes del cuerpo femenino que produce y reproduce la Escuela.

\section{De ayer nomás}

Según Simone de Beauvoir (1996), allá por el siglo IV Aristóteles consideraba que "la Mujer es Mujer en virtud de cierta falta de. Y debemos considerar el carácter de las mujeres como adoleciente de una imperfección natural" (Simone de Beauvoir, 1996: 4).

Es Giulia Sissa (1993), quien realiza un estudio historiográfico sobre las concepciones de los filósofos griegos respecto a las características diferenciadoras entre varones y mujeres. El filósofo griego consideraba que la mujer era un hombre defectuoso, frio, que nace por impotencia y es al mismo tiempo impotente. Pero lo más importante de su teoría es que la considera como un defecto en sí mismo, es un defecto de la naturaleza (Giulia Sissa, 1993: 94). El cuerpo de la mujer, según este parecer es pensado en comparación con el cuerpo del varón, por lo cual además de implementar el termino de diversidad, Aristóteles se refiere al sexo femenino como la imperfección de un modelo.

Ahora bien, nos cabe preguntar cuál era el motivo por el cual Aristóteles consideraba a la mujer como pequeña, más débil, con menos cabellos, blanda y prontamente flácida (Giulia Sissa, 1993: 94). Pues ello se debería a su frialdad, a una falta de calor vital que es del orden del metabolismo. Como advierte la autora trabajada, una parte o una demostración clave de esa frialdad sería la sangre de la menstruación, la cual es la más importante ya que aporta a la concepción de un hijo o hija. El griego realiza una equivalencia entre la menstruación y el esperma varonil, considerando que la sangre de la mujer se encuentra cruda por ser ella impotente; en cambio el esperma se encuentra cocido, así lo explicita Sissa (1993):

En esta coacción rápida, favorecida por el movimiento del coito precisamente antes de la eyaculación, crea una discontinuidad absoluta entre el residuo hemático y su derivado: a partir de ese momento, en el esperma habrá alma, forma, un principio de movimiento (Giulia Sissa, 1993: 97). 
En esta cita queda claro lo que nos ofrece la autora al pensar la filosofía de Aristóteles: el lugar principal queda relegado hacia el varón, quien a la hora de procrear es el que posee el alma, el movimiento, el principio generador de vida, mientras que la mujer es la poseedora tan solo del principio material que depende esencialmente del macho. Este último queda plasmado como el elemento activo, agente y motor, y la hembra como elemento pasivo, paciente y móvil, lo que se denomina como la teoría de la Mujer-vaso (Fernández, 1996: 67).

Dichas afirmaciones aristotélicas, lejos se encuentran de estar fundamentadas bajos discursos científicos-anatómicos, sino que por el contrario se tratan más bien de discursos puramente ideológicos sobre consideraciones que realizaban sobre el sexo femenino. Lo particular de su teoría, recae en lo que afirma Fernández (1996) cuando advierte que en realidad lo que se encuentra detrás de esta teoría discriminativa y opresiva no es más que el parecer social que existía en la Grecia de aquellos años hacia las mujeres. Por lo tanto, como son inferiores por naturaleza, porque así lo determina su cuerpo, son inferiores en todos los demás aspectos sociales.

Dentro de este esquema biológico- social de la mujer planteado desde la mitología griega de hace tantísimos años, es posible rastrear una de las enfermedades que históricamente se la ha vinculado exclusivamente con la mujer y su modo de relacionarse con la sexualidad.

De acuerdo a Fernández (1996), existen textos griegos que fueron conservados y que hoy en día podemos rastrear ciertas pesquisas sobre la histeria femenina. Dichos documentos pertenecían a los médicos que trabajaban con el sexo femenino, el modo que tenían para diagnosticar y determinar el tipo de enfermedad (o no) que padecían las mujeres era a partir de la explicación que las mismas realizaban a partir de sus síntomas y dolencias. Los mismos ni las observaban, ni las tocaban, sino que trataban de entender cuál sería el malestar de las mismas a partir de sus propias representaciones sobre el cuerpo femenino. Fueron solamente ellas quienes comenzaron a observar y conocer su propia corporeidad, no poseían un nombre específico pero solían decirles comadronas; los libros médicos expertos en el cuerpo de las mujeres son escritos que pertenecen a los varones, pero en verdad fueron estas mujeres que aportaron sus conocimientos al respecto.

Para estos médicos, la salud era comprendida a partir de una teoría llamada Medicina Hipocrática (Fernández ,1996:64), la cual abalaba que a partir del equilibrio de la bilis, el agua, la sangre y la flema; entendidos estos cuatro como las cuatro humores del cuerpo humano. A partir de estas descripciones en factible pensar cuál era la importancia que le otorgaban los griegos a la salud de la mujer que se encontraba en el momento de la menstruación, imposibilitadora esta de obtener el equilibrio saludable del sexo femenino. Al mismo tiempo, la regularidad de las relaciones sexuales también era partícipes de este momento insalubre de la mujer. 
Según Fernández (1998), aludiendo a Hipócrates, el cuerpo femenino tiene la particularidad de poseer un útero migrante, el mismo al no constar de relaciones sexuales con una frecuencia normal (ni mucho, ni poco), migrarían fatigados, cansados y vacíos hacia el diafragma, el cual también se encuentra liviano y vacío, constituyéndose de esta manera una de las enfermedades más típicas de las mujeres: la Histeria. De esta manera, advierte este médico griego, son generalmente las ancianas que sufren de sofocaciones debido a la compresión que se genera entre el diafragma y la matriz. (Fernández ,1996:64). Pero de igual manera, aquellas mujeres que poseen de gran actividad sexual, por lo cual no dejan en un estado de tranquilidad a su matriz, son propensas a contraer cualquier tipo de enfermedades. Se les recomienda a éstas que contraigan el matrimonio y el embarazo lo antes posible. Aquellas que aún no han sido desvirgadas antes de la menarca (primera menstruación) también deben tomar este consejo, ya que la sangre al no encontrar salida es disparadora de un arsenal de enfermedades.

Fernández (1996) sostiene, que aquí lo que se observar más allá de una teoría científica sobre el funcionamiento biológico de la mujer, es más bien una urgencia social, en el sentido que desde una perspectiva económica las familias necesitan que sus hijas ni bien poseedoras de condiciones biológicas contraigan matrimonio y tengan hijitos e hijitas, como una manera de soslayar los problemas económicos capitalistas. Pero en verdad estas decisiones que eran generalmente enmarcadas cuestiones médicas, consistían más bien en mandatos de moralidad.

\section{¿Cuerpos que importan?}

Para poder pensar estas características en el posmodernismo que nos toca atravesar y al mismo tiempo en las Instituciones Educativas actuales, hemos decidido plantearnos interrogantes acerca del cuerpo femenino adolescente escolarizado de comienzos del siglo XXI; y pensarlo a la vez, en vinculación a las contradicciones que de él se desprenden en función a los conceptos trabajados hasta el momento; es decir el mito del amor maternal que establece el equivalente irreductible del ser mujer con el ser madre, atravesada ésta por la función fisiológica extraordinaria de la menstruación.

Según Pinotti (1997) hoy Directora Centro de Investigaciones Sobre Problemáticas Alimentario Nutricionales, la mujer posee un cuerpo que se caracteriza por su espesor esponjoso y hasta almoadillento, cuya finalidad fundamental consiste en el almacenamiento de energía ya que la grasa proporcionalmente es mejor que los glúcidos a la hora de otorgar energía (Pinotti, 1997: 144).

En cuanto a la distribución de la masa corporal, la autora sostiene que va cambiando a partir que pasan los años de las y los niños hasta los 7 años. Una vez que se encuentran saliendo de esta edad, se lleva a cabo lo que médicamente se denomina "brote preadolescente del desarrollo del tejido adiposo que 
anuncia la llegada del estirón puberal" (Falkner 1986, en Pinotti, 1997: 145). Frente a la primavera de la edad puberal, de una manera diferente los varones comienzan a desarrollar mayor fibra muscular, mientras que las niñas acumulan más grasas (hasta un $120 \%$ de tejido graso) distribuidas fundamentalmente en las caderas, músculos, tórax y brazos. Estas características fisiológicas de las niñas son fundamentales para poseer las condiciones necesarias para comenzar con los ciclos menstruales y poder llevar a cabo, si así lo desea, la reproducción. Las hormonas femeninas estrógenos hacen de lo suyo durante la pubertad otorgándole a la adolescente "mamas, caderas, útero, vagina y glándulas vaginales asociadas" (Pinotti, 1997: 146), formaciones corporales necesarias para la función reproductora de la mujer.

Es factible observar símbolos de la Antigüedad, en las cuales con el afán de retratar a la maternidad, se representaban mujeres de contexturas obesas, con glúteos y mamas de gran espesor las cuales daban idea de que esa mujer se encontraba en condiciones fisiológicas y con la energía necesaria para tener hijos o hijas.

Morgade (2001) advierte que cuando las niñas y los niños comienzan a entrar a la pubertad resurge en ellos y en su entorno no solo una sintomatología de adolecer, sino también es el momento en que se configura todo un sistema de símbolos diferenciales hacia las mujeres y hacia los varones. Desde la perspectiva de género podríamos decir, que los familiares de estos púberes refuerzan en este momento el deber ser femenino y el deber ser masculino con juicios de valores y discursos sexistas.

Denominados como "grupo de riesgo" por Morgade (2001) ante los modelos hegemónicos genéricos, los adolescentes se encuentran vulnerables a indagaciones sobre su propia identificación, el presente y el futuro. En este panorama, los medios de comunicación cobran gran protagonismo al imponer modelos de vidas devenidas perfectas y sobre todo de cuerpos devenidos perfectos y que son comprados tanto por mujeres como por varones: "muestran imágenes que contribuyen a crear realidades" (Morgade, 2001:50).

Uno de los estereotipos difundidos e impuestos hasta el hartazgo desde los medios de comunicación consiste en un cuerpo extremadamente delgado; las niñas púberes que transitan por esta edad caracterizada por los cambios físicos y emocionales a fin de responder a estos parámetros de belleza llegan hasta el punto de poner en riesgo su salud. La anorexia y la bulimia son enfermedades bien esquemáticas de la presión que se ejerce desde los medios; se difunde que una mujer poseedora de cuerpos inalcanzables será protagonista de una vida plagada de éxito, dinero y amor.

Como hemos recorrido hasta el momento, mientras siglos anteriores el cuerpo corpulento con caderas y mamas grandes y una piel bien cuidada sin rastros de exposición al sol eran signos de salud y bienestar económico; actualmente desde el mundo del modelaje y la moda se construyó un nuevo 
modelo de feminidad estereotipada ahora, como mujer andrógina (Pinotti, 1997; 148). Este término que posee sus raíces en la antigua Grecia y se percata en el Banquete de Platón, hace alusión a un ser que se escapa del dualismo mujer-varón y que reunía en su cuerpo el sexo masculino y el femenino y/o masculino-masculino y femenino-femenino.

Se llega a esta conceptualización de la mujer de fines del siglo XX y comienzo del XXI cuando se observan mujeres mediáticas con un cuerpo "delgado, esbelto y masculino, de una juventud congelada y de una feminidad equívoca, casi andrógina" (Pinotti, 1997; 148). Se puede visualizar como la piel bronceada y el cuerpo musculoso son sinónimos de pertenecer a una clase social determinada que permite a la mujer gozar del tiempo libre y los recursos económicos necesarios para poder dedicarle tiempo a su cuerpo. La alimentación se desliga de los carbohidratos y las grasas ya que su consumo impediría el estereotipo buscado, se la reemplazan por la ingesta de frutas, yogures, y todo tipo de alimento light, que como afirma Pinotti (1997), aparte de ser más caros no aportan los nutrientes necesarios para una alimentación sana.

Ahora bien, como abordamos durante el desarrollo de este trabajo, la grasa corporal y determinadas condiciones fisiológicas y biológicas eran necesarias en la mujer para las funciones que determinan le fertilidad de las mismas. Nos preguntamos entonces: ¿Qué sucede con los mandatos sociales modernos de imposición maternal sobre las mujeres como el fin único de sus proyectos de vida? ¿Qué pasa con este nuevo cuerpo ineficiente para poder solventar el crecimiento de otro cuerpo?

\section{Conclusiones}

Remontándonos a nuestro planteo inicial aludiendo a una entrevista realizada hacia un alumno residente del Profesorado en Educación Física, quien ante la posibilidad de tener que vivenciar el momento (pareciera traumático) de la primera menstruación de una alumna, mujer y púber de $7^{\circ}$ grado; postulaba que él no debería estar en esas circunstancias, y que las púber/adolescentes deberían trabajar solamente con profesoras mujeres ( $\mathrm{y}$ a la inversa):

"Recién en una clase al lado mío había una nena que había menstruando por primera vez, puede ser un argumento ante la decisión de que las nenas en Educación Física tengan profesoras mujeres, y los varones profesores varones" (Estudiante del Profesorado en Educación Física, ISEF №11, 2013. Rosario).

La Escuela, como Institución socializadora y transmisora del Estado ha tenido y sigue teniendo una gran influencia en la reproducción estereotipada de los géneros. Esta perpetuación de modelos del deber ser se imponen en los y las alumnas ya sea desde los contenidos explícitos e implícitos como así también a partir de las distribuciones, modos y rituales que se establecen en el 
aula escolar. De esta manera, se lleva a cabo desde la Escuela no sólo todo un sistema de símbolos de los cuales son imposibles escapar porque de así serlo los y las llevaría al aislamiento y discriminación; sino también se establecen relaciones de poder entre los y las estudiantes.

Entendemos al género como interpretación cultural y social que realiza la sociedad sobre las relaciones que se establecen entre los hombres y las mujeres (John Scott, 1993). Dicho concepto adjudica que el dualismo mujer-varón no surge a partir de diferencias biológicas ni innatas, sino que son producto de los discursos hegemónicos que impusieron un deber ser arbitrario del ser mujer y un deber ser del varón. A la vez, los vínculos que establecieron estos dos polos genéricos se sustentaron de relaciones de poder en las cuales se determinó la sumisión de la mujer.

La filósofa pro-estructuralista, Butler Judith (2002) en función al género estableció la su teoría performativa, la cual establece que las normas y leyes reguladoras del sexo, actúan performativamente en la materialidad del cuerpo, entendiendo a esta última cómo un "un acto singular y deliberado, sino antes bien cómo la práctica reiterativa y referencial mediante la cual el discurso produce los efectos que nombra" (Butler, 2002: p18).

Respecto a ello, en nuestras Escuelas argentinas si logramos remontarnos a los inicios del Sistema Educativo y a la sanción de la Ley inaugural №1420 podemos advertir que si bien no se establecían en dicha norma ningún tipo de diferenciación en el modo de impartir educación para las niños y para las niñas; es factible visualizar como los varones de fines del siglo XIX desarrollaban "ejercicios militares" y las niñas que vivenciaron los mismos años dictaron clases de "labores domésticos" (Morgade, 2001: 59).

Ante este esquema, Vigarello (2005) sostiene que "las pedagogías son portadoras de preceptos que dan al cuerpo una forma y lo cuadriculan para someterlo a normas con mayor seguridad aun de lo que lo haría el pensamiento". (2005: .9) .A partir del discurso escolar como así también de movimientos o gestos que son transmitidos y que de una manera oculta, son inferidos hacia las y los alumnos; éstos llegan a considerarlo como una orden, una obligación a la cual la hacen propia y la inscriben corporalmente: "el cuerpo es el primer lugar donde la mano del adulto marca al niño, es el primer espacio donde se imponen los limites sociales y psicológicos que se le dan a su conducta, es el emblema donde la cultura inscribe sus signos como si fueran blasones" (Vigarrello, 2005: 9).

El Curriculum, entonces, se constituye como una pieza fundamental en cuanto es establecido como un dispositivo proclive para una educación enmarcada en intereses específicos, ya que se encuentra constituido por un conjunto de normas, conocimientos y prácticas que forman un instrumento de poder, en nuestro caso, sobre los cuerpos. 
Hoy en día, ya no existen disciplinas que sean consideradas curricularmente como propias de algún sexo biológico en general, pero lo que si existe y con una presencia bien fuerte como advierte Morgade (2001) son cuestiones silenciosas que pasan inadvertidas en las clases, pero que están y que suceden todos los días como parte cotidiana de la vida en las aulas; marcando fuertemente cuestiones estereotipadas que reciben los alumnos y las alumnas.

Si bien, estas cuestiones genéricas del deber ser puedan no ser mencionadas explícitamente por los o las docentes, es cierto que se encuentran en juicios de valores a un nivel de incorporación tan inconsciente y a la vez involuntarios que tal vez no llegan a detectarlos. Cuando hablamos de la permanencia de estas divisiones genéricas en la vida cotidiana nos referimos a su presencia en las distribuciones áulicas, en los contenidos obturados del discurso sexista, en los conocimientos que siempre fueron producidos por los varones, en el listado de asistencia que generalmente los varones siempre son quienes las encabezan y en tantas otras cosas que resultan muchísimas para mencionar en este trabajo; incluso en aquellas practicas educativas que son abatidas por el currículum nulo: "de eso no se habla", sin saber que detrás de ese silencio hay mil palabras gritando a viva voz.

En la cita que trajimos a colación como pretexto para sumergirnos en estos temas pedregosos y de tabúes, puede plasmarse como aquellos discursos de tantísimos años atrás siguen permeando a los sujetos del siglo XXI y lo hacen de un modo silencioso. Más aún si lo pensamos desde el área de la Educación Física, la cual consistente en una educación disciplinante sobre los cuerpos, constitutiva también de una producción y reproducciones de normas y valores basadas en estereotipos culturales homofóbicos, estigmatizantes y discriminativos.

Consideramos entonces, que el hecho de que futuros docentes consideren la necesidad de dividir a los alumnos de las alumnas (en este caso) por la existencia de posibles acontecimientos que no son más que productos de la biología y la fisiología de la mujer, forma parte de una reproducción sistemática del estereotipo hegemónico de la mujer. Si bien se ha avanzado mucho en cuestiones genéricas y sexuales en el marco de nuestras escuelas, este largo pero a la vez acotado análisis historiográfico sobre la mujer y su cuerpo nos han permitido visualizar las complejas cuestiones que actualmente entran en juego en las relaciones de poder con los varones y con otras mujeres, que al estar de una manera tan naturalizada muchas veces no llegamos a visualizarlas como tal.

Por ello, y finalmente, consideramos que es sumamente importante ahondar sobre las prescripciones que sufre el cuerpo de la mujer ya sea desde la sociedad y los medios de comunicación en general como así también desde las aulas en relación a los y las docentes en particular. Consideramos a la vez que las alumnas y los alumnos deben trabajar de manera mixta, en el marco de una coeducación en la cual la igualdad y los derechos se hagan presentes. 


\section{Referencias Bibliográficas}

- Álvarez, M., Pinotti, L.V., (1997). Procesos socioculturales y alimentación. Serie Antropológica Buenos Aires: Editorial del Sol.

- $\quad$ Ariés, P., Duby G. (2001). Historia de la vida privada. Francia: Editorial Taurus.

- $\quad$ Askew, S., Ross C., (1992). Los chicos no lloran. El sexismo en educación. Barcelona. Buenos Aires. México: Editorial Paidós.

- $\quad$ Badinter. E. (1981). ¿Existe el amor maternal? Historia del amor maternal. Siglos XVII al XX. Barcelona: Editorial Paidós.

- Burín M., Dio Bleichmar E. (1996). El ombligo del género. En Género, psicoanálisis y subjetividad. Buenos Aires: Editorial Paidós.

- Butler, J. (2002), Cuerpos que importan. Sobre los límites materiales y discursivos del "sexo", Ed Paidós, Argentina.

- Caballero Z. (1998) Tema de Mujeres. Definir la Coeducación: debates y desafíos. Centro de Estudios Históricos Interdisciplinarios sobre las Mujeres C.E.H.I.M. Universidad Nacional de Tucumán. Argentina.

- $\quad$ Caballero Z., (1996). Niñez y noción de género. Maestría: El poder y la sociedad desde el Enfoque de Género. Universidad Nacional de Rosario. Argentina.

- $\quad$ Carrión M. B., s/r. Diferentes perspectivas de cuerpo. Universidad Nacional de La Plata. Argentina.

- Ciriza A., (2007). Apuntes para una crítica feminista de los atolladeros del género. Revista anual de la Unidad de Historiografía e Historia de las Ideas - INCIHUSA / Mendoza Año $8 / \mathrm{N}^{\circ}$ 9. Argentina.

- De Beauvoir S., (1948-1949). El Segundo Sexo. Francia.

- Duby G., Perrot M. (1990). Historia de Mujeres. Tomo I: La Antigüedad Modelos Femeninos. Editorial Taurus.

- $\quad$ Fernández, A. M. (1996). De eso no se escucha: El género en el psicoanálisis. Buenos Aires: Editorial Paidós.

- Fernández, A. M. (1993). La mujer de la ilusión. Pactos y contratos entre hombres y mujeres. Buenos Aires: Editorial Paidós.

- Flax, J., (1990). Posmodernismo y relaciones de género en la teoría femenina. En Revista Feminaria.

- Lamas, M. (1986). La antropología feminista y la categoría género. En Revista Nueva Antropología, Vol VIII, N³0. México.

- $\quad$ Santos, M. A., (1998), Hacer visible lo cotidiano. Madrid: Ediciones Akal.

- Le Breton, D. (2002) La sociología del cuerpo. Buenos Aires: Editorial Nueva Visión.

- Martínez R., Del Valle Peinado E. (2010). Los usos del sexo en la escuela o como el campo escolar es un espacio donde el hábitus patriarcal se profundiza. Cuadernos FHyCS-UNJu, Nro. 38 (pp.127-143). Universidad Nacional de Jujuy. Argentina.

- Montserrat, M. (1986). Como se enseña a ser niña. El sexismo en la escuela. Barcelona: Editorial ICARIA.

- Morgade, G. (2006). Educación en la sexualidad desde el enfoque de género. Una antigua deuda de la escuela. En: Revista Novedades Educativas No 184, pp. 40-44. Buenos Aires.

- Morgade, G. (2011). Aprender a ser mujer. Aprender a ser varón. Buenos Aires: Editorial Noveduc.

- $\quad$ Pornea A. R. (1983). Del dominio del cuerpo a la privación sensorial. Francia: Editorial Península.

- $\quad$ Scott J., (2009). Género E Historia. s/r. México.

- Scott. J., Weed E., (2011). La cuestión de género: feminismo crítica. 
- Sena, C. (2010).Cuerpo interpretado como texto y prácticas corporales. Controversias en torno a la hermenéutica fenomenológica y las ciencias sociales en-carnadas. Universidad de Comahue, Bariloche. Argentina.

- Subiratas M. (1994). Conquistar la igualdad: la coeducación hoy. Revista Iberoamericana de Educación. $\mathrm{N}^{\circ} 6$. España.

- Subirats M., Brullet Cristina. (1988). Rosa y Azul. La transmisión de los géneros en la escuela mixta. Serie Estudios. España.

- $\quad$ Tubert, S. (1996). Figuras de la madre. Madrid: Editorial Cátedra.

- Volnovich, J. (2000). Claves de infancia. Ética y género en clínica psicoanalítica con niños. Quilmes: Homo Sapiens Ediciones. 